\title{
Adenocarcinoma of the Urinary Bladder in Egypt: Potential Risk Factors
}

\author{
Sania Amr ${ }^{\mathrm{a}}$, Christopher A. Loffredo ${ }^{\mathrm{b}}$, Kathleen M. McClain ${ }^{\mathrm{b}}$, \\ Bhaskar Kallakury ${ }^{\mathrm{b}}$, Yun-Ling Zheng ${ }^{\mathrm{b}, \mathrm{c}}$
}

\begin{abstract}
Background: Urothelial carcinoma (UC) and squamous cell carcinomas (SCC) of the urinary bladder have been well studied worldwide, but little is known about adenocarcinoma aside from its clinical features. Our objective was to examine associations between adenocarcinoma and known risk factors for UC and SCC in Egypt.

Methods: We used data from our multi-center case-control study in Egypt where questionnaires inquired about tobacco smoking, schistosomiasis and other exposures by 101 cases of bladder adenocarcinoma and 3,737 population-based controls. Logistic regression models estimated the adjusted odds ratio (AOR) and 95\% confidence interval (CI) of these associations.
\end{abstract}

Results: The mean (SD) age for adenocarcinoma was 55.3 (9.8) and 54.2 (11.3) among men and women, respectively. There was an association with schistosomiasis, albeit higher for women than for men (AOR (95\% CI): 4.58 (2.13 - 9.86) and 1.77 (1.05 - 2.98), respectively). Among men, smoking either cigarettes or water pipes was associated with adenocarcinoma (1.78 (0.85 - 3.75) or $1.97(0.79-4.91)$, respectively), and the highest risk (3.34 (1.38 - 8.09)) was among those who smoked both water pipes and cigarettes.

Conclusion: Smoking both cigarette and water pipe tobacco was associated with increased risk for adenocarcinoma of the bladder among males in this study, as was a history of schistosomiasis in both men and women.

Keywords: Bladder cancer; Adenocarcinoma; Tobacco smoking; Schistosomiasis; Epidemiology

Manuscript accepted for publication August 19, 2015

aDepartment of Epidemiology and Public Health, University of Maryland, Redwood St, Baltimore, MD 21201, USA

bLombardi Comprehensive Cancer Center, Georgetown University, 3970 Reservoir Rd NW, Washington, DC 20057, USA

${ }^{\mathrm{c} C}$ Corresponding Author: Yun-Ling Zheng, Lombardi Comprehensive Cancer Center, Georgetown University, 3970 Reservoir Rd, Washington, DC 20057, USA.Email: yz37@georgetown.edu

doi: http://dx.doi.org/10.14740/wjnu228w

\section{Introduction}

Urinary bladder cancer ranks seventh overall among men but 17th among women. In Egypt, it is the second leading cause of cancer death, with a mortality rate three times the rate in Europe and the United States [1], due to endemic schistosomiasis and male tobacco smoking [2].

Urinary bladder cancer subtypes include urothelial carcinoma (UC), squamous cell carcinoma (SCC), adenocarcinoma, anaplastic, and other rare forms. The most prevalent subtype is UC, accounting for about $90 \%$ of incident cases in developed countries. SCC, representing about $5 \%$ of all bladder cancer cases worldwide, is much more common in areas where schistosoma hematobium $(\mathrm{SH})$ infection is endemic, such as in Egypt where currently it accounts for over 30\% of the cases [2]. It is well established that cigarette smoking and occupational exposure to chemicals are major contributing factors to the development of UC, while SH infection accounts for most of SCC [3]. The risk factors for adenocarcinoma, which is characterized by its invasiveness and aggressive clinical presentation [4], are largely unknown, because of its rare occurrence in most populations, e.g. only $2 \%$ of cases.

Between 2006 and 2014, we conducted a large multicenter case-control study in Egypt, to address the risk factors associated with urinary bladder cancer and how they differ between men and women. We found that history of tobacco use, exposure to environmental tobacco smoke (ETS), and SH infection were associated with both UC and SCC among Egyptian men and women $[2,5,6]$. To address the gaps in epidemiologic information regarding adenocarcinoma of the urinary bladder, we examined the associations between the latter and potential risk factors in Egypt.

\section{Materials and Methods}

Detailed methods about the study have been previously reported [2]; key aspects of the study population and variables are summarized below.

The study was approved by the Institutional Review Boards of the three recruitment sites described below, Egypt's Ministry of Health, the University of Maryland Baltimore, and Georgetown University. Bladder cancer cases were recruited from three cancer centers in Egypt: the National Cancer Institute in Cairo, 
Table 1. Sociodemographic Characteristics of Adenocarcinoma Cases and Controls in Egypt Stratified by Gender

\begin{tabular}{|c|c|c|c|c|}
\hline \multirow{2}{*}{ Variable } & \multicolumn{2}{|c|}{ Men } & \multicolumn{2}{|c|}{ Women } \\
\hline & Controls $(\mathrm{N}=\mathbf{2 , 8 8 2})$ & Cases $(N=70)$ & Controls $(\mathrm{N}=\mathbf{8 5 5})$ & Cases $(N=31)$ \\
\hline Age, mean (SD) years & $58.5(11.9)$ & $55.3(9.8)$ & $54.5(13.0)$ & $54.2(11.3)$ \\
\hline \multicolumn{5}{|l|}{ Age group, n (\%) } \\
\hline$\leq 45$ & $399(13.8)$ & $13(18.6)$ & $224(26.2)$ & $10(32.3)$ \\
\hline $45-55$ & $762(26.4)$ & $27(38.6)$ & $229(26.8)$ & $6(19.3)$ \\
\hline $55-65$ & $935(32.5)$ & $21(30.0)$ & $252(29.5)$ & $11(35.5)$ \\
\hline$>65$ & $786(27.3)$ & $9(12.8)$ & $150(17.5)$ & $4(12.9)$ \\
\hline \multicolumn{5}{|l|}{ Residence, n (\%) } \\
\hline Urban & $256(8.9)$ & $7(10.0)$ & $110(12.9)$ & $3(9.7)$ \\
\hline Rural & $2,625(91.1)$ & $63(90.0)$ & $745(87.1)$ & $28(90.3)$ \\
\hline Missing & 1 & & & \\
\hline \multicolumn{5}{|c|}{ History of schistosomiasis, $\mathrm{n}(\%)$} \\
\hline No & $1,347(46.7)$ & $22(31.4)$ & $708(82.8)$ & $18(58.0)$ \\
\hline Yes & $1,373(47.7)$ & $45(64.3)$ & $98(11.5)$ & $12(38.7)$ \\
\hline Do not know & $162(5.6)$ & $3(4.3)$ & $49(5.7)$ & $1(3.2)$ \\
\hline \multicolumn{5}{|l|}{ History of UTI ${ }^{1} \mathrm{n}(\%)$} \\
\hline No & $2,408(83.6)$ & $50(71.4)$ & $707(82.7)$ & $20(64.5)$ \\
\hline Yes & $472(16.4)$ & $20(28.6)$ & $148(17.3)$ & $11(35.5)$ \\
\hline Missing & 2 & & & \\
\hline \multicolumn{5}{|l|}{ Smoking history, n (\%) } \\
\hline Never & $692(24.0)$ & $10(14.3)$ & $841(98.4)$ & $29(93.6)$ \\
\hline Water pipe only & $392(13.6)$ & $10(14.3)$ & $11(1.3)$ & 0 \\
\hline Cigarette only & $1,544(53.6)$ & $36(51.4)$ & $3(0.3)$ & $1(3.2)$ \\
\hline Both & $254(8.8)$ & $14(20.0)$ & 0 & $1(3.2)$ \\
\hline \multicolumn{5}{|c|}{ Among cigarette smokers only } \\
\hline Never n $(\%)$ & $692(31.0)$ & $10(21.7)$ & & \\
\hline Former & $483(21.6)$ & $12(26.1)$ & & \\
\hline Current & $1,059(47.4)$ & $24(52.2)$ & & \\
\hline Mean pack-years² (SD) & $32.8(18.5)$ & $27.8(16.5)^{3}$ & & \\
\hline$\leq 20$ pack-years, $\mathrm{n}(\%)$ & $432(28.9)$ & $14(38.9)$ & & \\
\hline$>20$ pack-years & $1,065(71.1)$ & $22(61.1)$ & & \\
\hline \multicolumn{5}{|l|}{ ETS 4 exposure, n (\%) } \\
\hline No & $297(42.9)$ & $2(20.0)$ & $804(95.6)$ & $28(96.5)$ \\
\hline Yes & $395(57.1)$ & $8(80.0)$ & $37(4.4)$ & $1(3.5)$ \\
\hline Missing & & & 14 & 2 \\
\hline
\end{tabular}

${ }^{1}$ Urinary tract infection other than schistosomiasis. ${ }^{2}$ Pack-years (product of the number of daily packs by the number of smoking years) of cigarettes. ${ }^{3} \mathrm{P}=0.1$ using $\mathrm{T}$ test. ${ }^{4}$ Environmental tobacco smoke among never smokers only.

the Minia Oncology Center in Minia, and the South Egypt Cancer Institute in Assiut. Cases were considered eligible if: they were diagnosed with primary bladder cancer within the last year, were between the ages of 19 and 80 years, and able to participate in an interview. Patients were excluded if they had a history of other cancers. For the cases, referred slides, or specimens collected from either biopsy or following surgical resection were reviewed by the pathologists and classified as: UC, SCC, adenocarcinoma, or other cancer types. This report includes only those cases that were confirmed as adenocarcinoma.

Controls were randomly selected from the population to frequency-match the cases on gender, age, and region of current residence. Controls were eligible if: they had no history of any cancer, were between the ages of 19 and 80 years, and were able to participate in an interview. The controls also underwent an ultrasound exam to check for any abdominal masses, including the bladder. There were two recruitment methods for the controls: random sampling of households and random 
Table 2. Associations Between Adenocarcinoma of the Urinary Bladder and History of Schistosomiasis and Other Urinary Tract Infection Among Egyptian Men and Women

\begin{tabular}{|c|c|c|}
\hline \multirow[t]{2}{*}{ Variable } & \multicolumn{2}{|c|}{$\begin{array}{l}\text { Adjusted odds ratios ( } 95 \% \\
\text { confidence interval) }\end{array}$} \\
\hline & Men & Women \\
\hline \multicolumn{3}{|c|}{ Schistosomiasis } \\
\hline No & Reference & Reference \\
\hline Yes & $1.77(1.05-2.98)$ & $4.58(2.13-9.86)$ \\
\hline \multicolumn{3}{|c|}{ Urinary tract infection } \\
\hline No & Reference & Reference \\
\hline Yes & $1.66(0.95-2.91)$ & $2.48(1.13-5.43)$ \\
\hline
\end{tabular}

In addition to the variables listed, the regression models included age for both men and women and smoking for men only.

sampling of family health records. The number of required controls and the necessary age and gender distributions were determined by the number of cases recruited per governorate, and controls were recruited as previously described [2].

The study was explained to the eligible subjects, and those who agreed to participate signed a consent form. Trained interviewers administered a questionnaire to obtain information on socio-demographic characteristics, occupational and environmental exposure histories, tobacco smoking (cigarettes, water pipes, or both, and ETS), and medical history including history of SH infection and other urinary tract infections (UTI).

The tobacco use variables were only analyzed in men because women seldom reported using any tobacco products. Tobacco use was divided into four categories: "never users", "water pipe only", "cigarette only", and users of "both water pipe and cigarette". "Never users" were defined as those participants who had never smoked a water pipe and had smoked less than 100 cigarettes in their lifetime. Cigarette smoking was analyzed using the following variables: cigarette smoking status, categorized as "never," "former" (quit for at least 1 year prior to interview), and "current" smokers. We also calculate pack-years of cigarettes smoked as the product of the number of daily packs by the number of smoking years. ETS exposure was categorized as: "no exposure", or "exposure at either home or outside the home".

We used multivariable logistic regression models to estimate adjusted odds ratio (AOR) and 95\% confidence interval (CI): all models were stratified by gender and adjusted for age. All analyses were conducted using SAS software, version 9.3 (SAS Institute Inc., Cary, NC).

\section{Results}

Of the 2,347 total bladder cancer cases in our study confirmed by pathology review as primary bladder cancer malignancies, $101(4.3 \%)$ were adenocarcinoma.

Table 1 displays the demographic characteristics of the study population, separately for males and females. The cases included 70 males and 31 females (approximately 2.2:1 ratio).
Table 3. Associations Between Adenocarcinoma of the Urinary Bladder and Smoking Among Men in Egypt

\begin{tabular}{ll} 
Smoking variable & $\begin{array}{l}\text { Adjusted odds ratios } \mathbf{( 9 5 \%} \\
\text { confidence interval) }\end{array}$ \\
\hline None & Reference \\
Water pipe only & $1.97(0.79-4.91)^{1}$ \\
\hline Cigarette only & $1.78(0.85-3.75)$ \\
Both & $3.34(1.38-8.09)$ \\
Smoking cigarettes only & \\
\multicolumn{1}{l}{ None } & Reference \\
$\quad \leq 20$ pack-years & $2.28(0.96-5.43)$ \\
$\quad>20$ pack-years & $1.72(0.78-3.81)$ \\
Smoking cigarettes only & \\
\multicolumn{1}{l}{ None } & Reference \\
\multicolumn{1}{l}{ Former } & $1.67(0.77-3.65)$ \\
$\quad$ Current & $1.95(0.79-4.77)$ \\
\hline
\end{tabular}

${ }^{1}$ Adjusted for age, history of schistosomiasis and urinary tract infection.

The mean ages of cases were significantly $(\mathrm{P}=0.01)$ younger (55.3) than the controls (58.5) among men, but not among women (54.2) $(\mathrm{P}=0.8)$. The proportions of men who reported history of schistosomiasis $(64 \%$ and $47 \%)$ were higher than those of women (38\% and 11\%) among cases and controls, respectively (Table 1). Smoking was highly prevalent among men $(>70 \%$ ever smoked and approximately half of them were current cigarette smokers), but rare among women (Table 1). On an average, the cases who used only cigarettes smoked $27.8 \pm 16.5$ (mean \pm SD) pack-years of cigarettes, while the controls smoked $32.8 \pm 18.5$, not statistically significantly different $(\mathrm{P}=0.1)$.

The majority of tumors $(83 \%$ and $80 \%$ among men and women, respectively) were characterized as grade 2 or 3 . Examination of the pathology specimen revealed evidence of $\mathrm{SH}$ infection in $38 \%$ of the cases regardless of their gender.

History of schistosomiasis was significantly associated with adenocarcinoma of the bladder in both women and men, although the magnitude of the association was greater among the former as compared to the latter (AOR (95\% CI): 4.58 (2.13 - 9.86) and 1.97 (1.08 - 3.58), respectively). Similarly, UTI other than schistosomiasis was also associated with adenocarcinoma of the bladder (adjusted OR (95\% CI): 2.48 $(1.13-5.43)$ and $1.66(0.95-2.91)$, for women and men, respectively) (Table 2).

Eighty-five percent $(60 / 70)$ of male cases reported a history of any type of tobacco smoking compared to $76 \%$ of controls. Smoking water pipe tobacco was associated with increased risk of having adenocarcinoma even after adjustment for history of SH infection, UTI and age (AOR (95\% CI): 1.97 $(0.79-4.91))$. The highest risk was observed among those who smoked both cigarettes and water pipes (3.34 (1.38 - 8.09)) (Table 3 ). The number of pack-years of smoking cigarettes was inversely associated with the risk of adenocarcinoma; the AOR for men who smoked less than 20 pack-years was higher than the AOR of those who smoked more than 20 (Table 3 ). 
The number of those who smoked only water pipes was too small to allow meaningful analysis, and so was the number of women who reported smoking (two among cases and 14 among controls).

\section{Discussion}

This study is one of the few epidemiologic case-control studies focusing on adenocarcinoma of the bladder. We found that smoking, schistosomiasis, and UTI among men, and schistosomiasis and UTI among women, increased the risk for adenocarcinoma, a rare form of urinary bladder cancer. These factors have been previously reported as contributing to the risk of UC and SCC in Egypt (7 - 9), and elsewhere (10 - 12), with the exception of schistosomiasis which is not endemic in most countries where epidemiological studies were performed. Egyptian men who smoked both cigarettes and water pipes had three times greater risk (OR: 3.34) of developing adenocarcinoma than men who did not smoke either type of tobacco. This result is similar to what we observed for UC and to a lesser extent SCC in Egypt [2]. Thus it appears that tobacco smoking is a commonly associated exposure across all the major subtypes of bladder cancer.

Adenocarcinoma, like SCC, appears to occur at a younger age than UC. Indeed the mean ages for men and women were respectively 54.3 and 54.2 , significantly younger than the mean ages we reported for UC, 61.3 and 60.2, respectively [2]. Similarly, Lughezzani et al [13] reported a younger age at diagnosis in an SEER-based series of 306 adenocarcinoma cases compared to nearly $12,000 \mathrm{UC}$, but did not report gender-specific age differences. Compared to SCC and $\mathrm{UC}$, we found a smaller male/female ratio, i.e. 2:1 in adenocarcinoma versus 3:1 for SCC and 6:1 for UC in Egypt [2], and this smaller ratio was nearly identical to that reported by Lughezzani et al [13].

We found a significant association between history of schistosomiasis infection and increased risk of adenocarcinoma in both men (OR: 1.7) and women (4.5), an increased risk that was comparable to that for SCC risk, among men (1.4), but greater among women (1.9) [2].

In one of the largest reported case series of adenocarcinoma, El Mekresh et al [14] described 185 consecutive cases presenting in Mansoura, Egypt, a high incidence area for bladder cancer: $82 \%$ of the surgical specimens were positive for schistosomal eggs, confirming a possible etiological role for this potential risk factor, but male-female differences were not reported. In our study, we found evidence for SH infection only in $38 \%$ or the pathological specimens, regardless of gender.

The odds of having adenocarcinoma were higher among women than among men who reported a history of UTI other than schistosomiasis. In the US SEER-based study reported by Kantor et al [10], cigarette smoking and UTIs were associated with increased risk of SCC but not with adenocarcinoma; the study's sample size was too small to draw conclusions about gender differences.

This study has some notable strength, including the confirmation of cases by a pathologist's standardized review of surgical and biopsy specimens, and the population-based recruit- ment of controls. Nonetheless, the relatively small number of cases, especially when stratified by gender, limited our ability to discern statistically significant associations with other potential risk factors. There were some inconsistencies in the associations with self-reported tobacco smoking history: despite the overall higher prevalence of current and former smoking by cases than controls, the mean pack-years was somewhat higher for controls, which may possibly reflect recent quitting among the cases due to the effects of the cancer.

\section{Acknowledgement}

The authors thank Drs. Iman Gouda and ImanLoay of the NCICairo who evaluated the pathology of all the cases. We thank Dr. Nabiel N. Mikhail for data management and for supervising case and control recruitment in Assiut, and Drs. Doa'a Saleh and Sameera Ezzat for supervising and coordinating the field staff in Cairo and Minia.

\section{Grant Support}

This research was supported by the US National Cancer Institute (grant numbers R01CA115618 and R01CA132996).

\section{Conflict of Interest}

None of the authors declare any conflicts of interest.

\section{References}

1. GLOBOCAN 2012: Estimated cancer incidence, mortality and prevalence worldwide in 2012[internet]. Lyon, France: Interagency for Research on Cancer/World Health Organization; 2012 [updated 2015]; cited 2014 September 29. Available from: http://globocan.iarc.fr/ Pages/fact sheets population.aspx.

2. Zheng YL, Amr S, Saleh DA, Dash C, Ezzat S, Mikhail NN, Gouda I, et al. Urinary bladder cancer risk factors in Egypt: a multicenter case-control study. Cancer Epidemiol Biomarkers Prev. 2012;21(3):537-546.

3. Kiriluk KJ, Prasad SM, Patel AR, Steinberg GD, Smith ND. Bladder cancer risk from occupational and environmental exposures. Urol Oncol. 2012;30(2):199-211.

4. Burnett AL, Epstein JI, Marshall FF. Adenocarcinoma of urinary bladder: classification and management. Urology. 1991;37(4):315-321.

5. Goerlitz D, Amr S, Dash C, Saleh DA, El Daly M, AbdelHamid M, El Kafrawy S, et al. Genetic polymorphisms in NQO1 and SOD2: interactions with smoking, schistosoma infection, and bladder cancer risk in Egypt. Urol Oncol. 2014;32(1):47 e15-20.

6. Amr S, Dawson R, Saleh DA, Magder LS, Mikhail NN, St George DM, Squibb K, et al. Agricultural workers and urinary bladder cancer risk in Egypt. Arch Environ Occup 
Health. 2014;69(1):3-10.

7. Badawi AF, Mostafa MH, Probert A, O'Connor PJ. Role of schistosomiasis in human bladder cancer: evidence of association, aetiological factors, and basic mechanisms of carcinogenesis. Eur J Cancer Prev. 1995;4(1):45-59.

8. Bedwani R, el-Khwsky F, Renganathan E, Braga C, Abu Seif HH, Abul Azm T, Zaki A, et al. Epidemiology of bladder cancer in Alexandria, Egypt: tobacco smoking. Int J Cancer. 1997;73(1):64-67.

9. Bedwani R, Renganathan E, El Kwhsky F, Braga C, Abu Seif HH, Abul Azm T, Zaki A, et al. Schistosomiasis and the risk of bladder cancer in Alexandria, Egypt. Br J Cancer. 1998;77(7):1186-1189.

10. Kantor AF, Hartge P, Hoover RN, Fraumeni JF, Jr. Epidemiological characteristics of squamous cell carcinoma and adenocarcinoma of the bladder. Cancer Res. 1988;48(13):3853-3855.
11. Brennan P, Bogillot O, Cordier S, Greiser E, Schill W, Vineis P, Lopez-Abente G, et al. Cigarette smoking and bladder cancer in men: a pooled analysis of 11 case-control studies. Int J Cancer. 2000;86(2):289-294.

12. Samanic C, Kogevinas M, Dosemeci M, Malats N, Real FX, Garcia-Closas M, Serra C, et al. Smoking and bladder cancer in Spain: effects of tobacco type, timing, environmental tobacco smoke, and gender. Cancer Epidemiol Biomarkers Prev. 2006;15(7):1348-1354.

13. Lughezzani G, Sun M, Jeldres C, Alasker A, Budaus L, Shariat SF, Latour M, et al. Adenocarcinoma versus urothelial carcinoma of the urinary bladder: comparison between pathologic stage at radical cystectomy and cancer-specific mortality. Urology. 2010;75(2):376-381.

14. el-Mekresh MM, el-Baz MA, Abol-Enein H, Ghoneim MA. Primary adenocarcinoma of the urinary bladder: a report of 185 cases. Br J Urol. 1998;82(2):206-212. 